\title{
Palestinian Working WomanSociety for Development: um estudo de caso sobre a resistência não violenta palestina.
}

\author{
Helena Sabino Rodrigues Cunha ${ }^{1}$
}

\begin{abstract}
Resumo
O presente trabalho pretende analisar a resistência não violenta presente na Palestina, dando uma ênfase ao movimento de resistência protagonizado por mulheres. Trata-se de estudo de caso realizado com a ONG Palestinian Working Woman Society for Development (PWWSD), uma das principais organizações de mulheres presentes nos Territórios Palestinos Ocupados.O estudo foi realizado a partir de pesquisa bibliográfica sobre resistência não-violenta, partindo, sobretudo, da perspectiva de Gene Sharp, e sobre o movimento de mulheres palestinas, baseado nas contribuições de Ellen Fleishman, Shadi Wadi, IslahJad e Rosemary Sayigh, entre outras. A análise da ONG se deu com base em relatórios disponíveis em seu site, referentes aos trabalhos realizados pela organização em 2013 e 2014, entrevista realizada com uma integrante da organização em fevereiro de 2016 e a partir da leitura de demais materiais publicados pela PWWSD (folders e informações disponíveis no seu site). A hipótese testada é de que o movimento de mulheres palestinas possui uma ampla tradição de resistência não violenta e que a PWWSD se insere de forma paradigmática neste contexto. Ao analisar a literatura referente à resistência não violenta no contexto específico da Palestina, notamos uma diferença de abordagem entre os estudos realizados antes e depois dos Acordos de Oslo, sendo os primeiros mais confiantes nesse tipo de resistência como ferramenta para superação da dominação israelense. Em relação ao movimento de mulheres palestinas, analisamos a presença desse tipo de resistência desde o início da colonização sionista e, com maior nível de detalhe, nos trabalhos desenvolvidos pela PWWSD.
\end{abstract}

Palavras-chave: Palestina, Resistência não violenta, Movimento de mulheres, PWWSD.

\section{Abstract}

The present work aims to analyse the nonviolent resistance present in Palestine, giving an emphasis to the resistance movement in which women play the leading role. This is a case study realized with the NGO Palestinian Working Woman Society for Development (PWWSD), one of the main women organizations based at the Palestinian Occupied Territories.The study was realized through bibliographical research about nonviolent resistance, mainly from Gene Sharp's perspective, and about the Palestinian women movement, from the contributions of Ellen Fleishman, ShadiWadi, IslahJad and Rosemary Sayigh, among others. The NGO's analysis was based on reports that refer to the work done by the organization during 2013 and 2014, an interview realized with one NGO's member in

\footnotetext{
${ }^{1}$ Bacharelado em Relações Internacionais - Instituto de Relações Internacionais/ Universidade de São Paulo. Bolsista de Iniciação Científica - bolsa FFLCH. helena.cunha@usp.br.
} 
February of 2016 and on the reading of other material published by PWWSD (such as folders and its website). The tested hypothesis is that the Palestinian women movement has a large tradition of nonviolent resistance and that PWWSD inserts itself in this context in a paradigmatic manner.Considering the literature referring to nonviolent resistance in the context of Palestine, we have noted a difference of approach between the studies realized before and after the Oslo Accords. The former seem to be more confident in this kind of resistance as a tool of overcoming the Israeli domination. In relation to the Palestinian women movement, we have analysed the presence of this kind of resistance since the beginning of Zionist colonization and, with a greater level of detail, at the work developed by PWWSD.

Key words: Palestine, Nonviolent resistance, Women's movement, PWWSD.

\section{Introdução}

O discurso da guerra ao terror, que passou a ganhar força principalmente depois dos atentados de 11 de setembro de 2001, tem servido de justificava para enormes investimentos das grandes potências mundiais nas indústrias bélica e de segurança nas últimas décadas, criando um novo paradigma de segurança internacional (DUARTE, 2011). Construído a partir de preconceitos e estereótipos, o discurso não apenas fundamenta a indústria armamentista, como as alianças preferenciais e investimentos, feitos pelos Estados Unidos, Rússia e potências regionais em todo o Oriente Médio. Também tem sido utilizado por Israel para justificar a ampliação de seus gastos militares (CHOMSKY, 2005).

$\mathrm{Na}$ Palestina, o fracasso do Processo de $\mathrm{Paz}_{\text {de }} \mathrm{Oslo}^{2}$ e a piora nas condições de vida da população desembocaram mais recentemente em um sentimento de frustração, falta de perspectiva de vida, e revolta diante da ocupação militar israelense da Cisjordânia, que são, ao que tudo indica, os principais fatores por trás da recente Intifada das facas (COSTA, 2015). Desde outubro de 2015, a Intifada das facas (como ficou conhecida a série de ataques a facadas que vem ocorrendo em Israel e nos Territórios Ocupados contra soldados e civis israelenses) tem apontado para o crescimento dos níveis de violência individual, com pouca influência da liderança tradicional palestina (FLINT, 2015).

Mas, ao contrário do que a mídia parece indicar, a Palestina possui uma longa tradição de resistência não violenta, desde as manifestações contra o Mandato britânico no início do

\footnotetext{
${ }^{2}$ Em 1993, delegados palestinos e israelenses iniciaram em Oslo a formalização de um acordo entre Yasser Arafat, liderança da Organização para Libertação da Palestina (OLP) e Yitzhak Rabin, então primeiro-ministro israelense. Os acordos previam, dentre outras coisas, o início de negociações sobre um tratado de paz no transcorrer máximo de cinco anos (ABU-EL-HAJ, 2014). Os resultados práticos do acordo, no entanto, foram menos otimistas. Foi criada a Autoridade Palestina, que deveria ser capaz de administrar a vida da população palestina nos aspectos básicos, como fornecimento de saúde e educação, enquanto Israel manteria controle militar sobre a maior parte do território palestino. Segundo Said (1993), os acordos de Oslo foram "um instrumento da rendição palestina, um Versalhes palestino".
} 
século XX, passando pelos comitês populares atuantes na Primeira Intifada (1987-1993), o primeiro grande levante não violento deflagrado nos Territórios Ocupados e que desafiou a ocupação militar israelense com revoltas contra impostos, greves gerais e boicotes (MAST; EL-ZABRI, 2015), até chegar às diversas organizações de base e de setores da sociedade, como as organizações de mulheres ${ }^{3}$.

O presente trabalho propõe uma investigação sobre a contribuição dos movimentos palestinos por direitos civis e de resistência não violenta para a superação da dominação israelense. Trata-se de estudo de caso realizado com a ONG Palestinian Working Woman Society for Development (PWWSD), desenvolvido com base em experiência de vivência junto à organização durante o mês de fevereiro de 2016.

O estudo foi realizado a partir de pesquisa bibliográfica sobre resistência não-violenta e sobre o movimento de mulheres palestinas. A análise da ONG se deu com base em relatórios disponíveis em seu site, referentes aos trabalhos realizados pela organização em 2013 e 2014, entrevista realizada com uma integrante da organização em fevereiro de 2016 e a partir da leitura de demais materiais da organização (folders e informações disponíveis no seu site)

Criada em 1981, como a "União dos comitês das mulheres trabalhadoras palestinas", a organização foi registrada no Ministério de Interior Palestino apenas em 2001. Seus objetivos principais são a contribuição para o empoderamento de mulheres, o aperfeiçoamento de seu bem-estar psicológico junto à comunidade e o combate à violência de gênero, e o desenvolvimento dos recursos e da capacidade da organização para fortalecer sua autossuficiência.

Com escritórios nas principais cidades palestinas (Ramallah, Nablus, Jenin, Tulkarem, Belém, Gaza e Yatta), a PWWSD consiste hoje em uma das mais importantes organizações atuantes nos Territórios Palestinos Ocupados e possui programas que visam a desenvolver seus objetivos junto às populações mais vulneráveis da Palestina. ${ }^{4}$

Este relatório se divide em três seções. Em um primeiro momento, apresentamos a literatura referente à concepção de resistência não violenta e sobre como esta se insere no contexto da Palestina. Na segunda seção, dissertamos sobre o movimento de mulheres palestinas e analisamos a atuação da Palestinian Working Woman Society neste contexto. Por

\footnotetext{
${ }^{3}$ Para mais informações sobre a resistência não violenta na Palestina, ver MIDDLE EAST TASK FORCE. Palestinian nonviolent resistance to occupation since 1967.AFSC Middle East Resource series, 2005.

${ }^{4}$ Informações disponíveis em: http://www.pwwsd.org/
} 
fim, apresentamos as principais conclusões acerca da resistência não violenta na Palestina e do trabalho realizado pela PWWSD.

\section{A resistência não violenta na Palestina.}

A resistência não violenta é um tipo de resistência muito mais comum do que se imagina, pois pode se manifestar de diversas formas. Desse modo, encontramos uma ampla diversidade na literatura no que se refere à sua definição. Para Awad, por exemplo, a resistência não violenta é "uma operação ativa e afirmativa, uma forma de conflito móvel (AWAD, 1984, p. 25). Dudouet, por sua vez, argumenta que a resistência não violenta “deveria ser vista como parte integral do processo de transformação de conflito, focando no diálogo, resolução de problemas e a restauração de relações de cooperação" (DUDOUET, 2008, p.2).

Erica Chenoweth e Maria J. Stephan (2014), a partir de um levantamento de dados realizado com a observação de 323 eventos de resistência não violenta, chegaram a três características comuns presentes nesse tipo de movimento. São elas: a maior participação das massas, a grande possibilidade de deserção do apoio político ao regime e o emprego de táticas flexíveis. Ainda segundo as autoras, são essas características que permitem que a resistência não violenta tenha mais chances de ser bem-sucedida do que a violência.

No entanto, para que seja efetiva, a resistência não violenta requer uma organização. Chenoweth e Stephan apontam para a presença desse tipo de resistência nos bastidores da Primavera Árabe:

\footnotetext{
Mas a resistência civil requer mais do que somente a participação das massas e as deserções; são também necessárias táticas planejadas e coordenadas. Movimentos não violentos bem sucedidos são raramente espontâneos, e o aparentemente rápido colapso dos regimes de Ben Ali e de Mubarak não deve enganar observadores: ambas as revoluções tiveram suas raízes em movimentos de trabalhadores e de oposição a esses regimes com início no mínimo uma década antes. (CHENOWETH; STEPHAN, 2014, tradução nossa).
}

Desse modo, ao contrário do que se pode supor, a resistência não violenta não consiste apenas em atos espontâneos e despolitizados, mas sim uma estratégia que requer amplo debate político e ação organizada das massas.

Dentre a literatura especializada em resistência não violenta na Palestina, temos a discussão realizada por Andrew Rigby,(2010), que classifica as técnicas mais utilizadas nos Territórios Palestinos Ocupados. Para o autor, a greve e a passeata podem ser englobadas no 
que ele chama de resistência ofensiva, cuja premissa é fazer o possível para frustrar o opressor a partir de técnicas não violentas, ou ainda na categoria de resistência polêmica, que consiste no "ato de dar voz a algum protesto e, dessa forma, mostrar para as pessoas a necessidade de manter uma batalha" (RIGBY, 2010, p.3).

A resistência não violenta pode se expressar também, segundo o autor, de maneira passiva, através, por exemplo, de atos de suporte e solidariedade a uma causa. Essas ações, além de serem importantes para fortalecer a unidade entre palestinos, contribuem para "reduzir o impacto da opressão e das punições israelenses ao envolver um grande número de pessoas, escalar um confronto com as autoridades e criar "pontos de contato ${ }^{5}$, de modo a apoiar a luta palestina" (AWAD, 1984, p.33). É possível traçar aqui um paralelo com a "resistência defensiva" de Rigby (2010), que consiste na proteção de valores humanos ameaçados pela ocupação, através, por exemplo, de auxílio a pessoas em perigo.

A tipificação adotada por Andrew Rigby (2010) leva em consideração o histórico da resistência palestina, desde as primeiras levas de migrantes judeus durante o Império Otomano, ainda no século XIX, até as formas de luta mais atuais. A partir dela, é possível perceber a dualidade da resistência não violenta, que pode se apresentar tanto de forma ativa como passiva.

Yousef Munayyer enfatiza esta última forma de resistência. Para ele, qualquer palestino vivendo sob a ocupação israelense é um resistente não violento, uma vez que o objetivo de Israel é fazer os palestinos abandonarem sua terra. A palavra árabe sumud é frequentemente utilizada em referência à resistência diária dos palestinos frente à ocupação.

Partimos, no entanto, da concepção de Sharp (1989) de que se trata de uma técnica de condução de conflitos que utiliza armas psicológicas, sociais e políticas, envolvendo três classes de métodos: formas simbólicas de protesto não violento (como vigílias, marchas e bandeiras); não cooperação (incluindo boicotes sociais e econômicos, greves de trabalhadores e outras formas de não cooperação política) e intervenção não violenta (estendendo-se de greves de fome a ocupações e bloqueios não violentos, criação de instituições independentes e estabelecimento de um governo paralelo). Optamos também por adotar a concepção de poder político de Sharp, segundo a qual, não deve ser algo monolítico, ou seja, que parta da ideia de que as pessoas dependem da boa vontade do governante. Pelo contrário, para o autor, a base fundamental da resistência não violenta é

\footnotetext{
${ }^{5}$ Segundo Awad, "um dos objetivos mais importantes de qualquer movimento não violento é encontrar pontos de contato entre os cidadãos e as autoridades que evidenciem o mal e a opressão por um lado, e que levem para um confronto útil e significativo, por outro (AWAD, 1984, p. 26)".
} 
[...] a crença de que o exercício do poder depende do consentimento do governado que, ao retirar seu consentimento, pode controlar e até mesmo destruir o poder do adversário mediante meios não violentos de exercer poder (SHARP, 1983, p. 12).

A resistência não violenta, portanto, constitui uma importante face da resistência palestina, no entanto, frequentemente silenciada. A atuação das mulheres nesse tipo de resistência é ainda menos conhecida, dado todo o peso da construção ocidental da imagem da mulher do Oriente. Organizações da sociedade civil que atuam pelo empoderamento e pela capacitação de mulheres ganham força dentro da Palestina, o que demonstra a necessidade de buscar compreendê-las mais a fundo.

\section{A atuação das mulheres no movimento de resistência não-violenta: um estudo de caso da Palestinian Working Woman Society for Development (PWWSD)}

O movimento de mulheres constitui-se como um dos grandes pilares da resistência não violenta na Palestina. Apesar da escassez de pesquisas específicas sobre a questão, alguns estudos (KAZI, 1987; WADI, 2009) fazem referência ao ano de 1884 como a primeira vez em que as mulheres palestinas deixaram suas casas para participar do movimento de resistência política, em resposta ao estabelecimento dos primeiros assentamentos sionistas na região. Em 1917, no entanto, à luz da Declaração Balfour ${ }^{6}$ e do aparecimento de milícias judaicas na Palestina, o movimento de resistência nacional palestino começou a se fortificar e as mulheres passaram a participar das grandes manifestações de rua.

A literatura aponta para 1921 como o ano de criação da primeira organização de mulheres palestinas. Nesse momento, o movimento de mulheres ainda era extremamente pautado por questões nacionalistas, em detrimento de assuntos que questionavam o papel das mulheres na sociedade palestina.

Em 1929, foi organizado o primeiro Congresso Feminista na Palestina, do qual resultou uma carta final, que foi encaminhada ao Alto Comissariado Britânico.Além disso, foi formada uma comissão para executar e administrar as resoluções do congresso. Segundo Ellen Fleischmann (2000, p. 19), "um dos principais objetivos do congresso foi especificamente agir como um catalisador para as mulheres de toda a Palestina organizarem seu próprio movimento".

Observando as agendas que resultaram do congresso, é possível notar que a agenda feminista existe (WADI, 2009), embora focasse primeiramente na questão nacional. Desse

\footnotetext{
${ }^{6}$ Declaração emitida pelo então Ministro britânico Arthur Balfour, que oficializa o apoio da Inglaterra para a construção de um Estado judaico na Palestina.
} 
modo, nota-se o duplo papel cumprido pelo Congresso Feminista de 1929: impulsionou a organização política de mulheres de forma deliberada, através da criação da Associação de Mulheres Árabes, e colocou a discussão sobre gênero em pauta.

Outra importante conquista do congresso foi fomentar a articulação das mulheres palestinas com feministas de diversas partes do Oriente Médio, como Egito, Iraque e Síria. Segundo ShadiWadi,

Os anos trinta ficaram marcados pelos muitos contactos que as mulheres palestinianas fizeram com outras mulheres árabes, como a sua presença nos vários congressos árabes, como Beirute em 1930 e Damasco e Bagdad em 1932 (WADI, 2009 , p. 15).

A escolarização das mulheres, principalmente nas áreas urbanas, teve papel fundamental na formação de sua autoconfiança para que se organizassem, falassem em público e enviassem petições às autoridades do mandato (SAYIGH, 2014). No entanto, conforme nota Laila al-Hamdani (2014), esse movimento era "confinado a mulheres urbanas que tiveram oportunidade de receber educação ou se relacionavam de alguma maneira com homens ativos na vida política, a elite."

Não se pode omitir, no entanto, a originalidade de suas ações com a visão de que essas mulheres agiam apenas dentro dos seus limites de classe. Ou seja, com a visão de que se tratavam de mulheres da elite palestina que agiam para mudar sua própria condição de vida, em detrimento das camadas menos privilegiadas da sociedade. Muitas das organizadoras da Associação de Mulheres Árabes escondiam prisioneiros fugitivos, participavam dos julgamentos, escreviam para a imprensa nacionalista e participavam de passeatas. "Algumas também desafiavam a convenção ao permanecerem solteiras ou casarem-se para além dos limites estabelecidos pela religião" (SAYIGH, 2014).

Embora se tenha conhecimento sobre o papel de vanguarda que as mulheres tiveram durante a Greve Geral de 1936 (SAYIGH, 2014), uma das maiores manifestações da resistência não violenta palestina, há poucos estudos sobre a composição social das mulheres que participaram do movimento. Foi somente durante a chamada Revolta Árabe (1936-1939), levada a cabo em decorrência da greve, que as mulheres camponesas deixaram o espaço privado e passaram a seu juntar aos homens no campo de batalha, embora seu papel fosse limitado a atividades como o transporte de armas e alimentos (JAD, 2005).

Em 1948, com a diáspora resultante do estabelecimento do Estado judaico na Palestina, pelo menos 10.000 palestinos foram mortos, enquanto $60 \%$ da população foi tirada de seu lar. Milhares de pessoas passaram, então, a viver em campos de refugiados, em estado 
de pobreza. Segundo IslahJad, "os homens tendiam a abandonar os campos em busca de empregos, tornando os campos um refúgio para mulheres, crianças e idosos" (JAD, 2005, p.219).

Desse modo, a vida econômica das mulheres refugiadas foi transformada e essa mudança cumpriu um papel no desenvolvimento da independência das mulheres e de uma consciência política (SAYIGH, 2014). Apesar disso, atividades de caridade, de caráter político superficial ainda eram dominantes nesse período, protagonizadas por mulheres burguesas. A resistência significava a perda de tudo e poucas oportunidades existiam para as mulheres pobres que viviam nos campos (KAZI, 1987).

Rosemary Sayigh (2014) aponta para cinco principais características do papel das mulheres na sociedade palestina pós-1948: as mulheres estavam principalmente no trabalho de assistência social; algumas entraram nos partidos políticos banidos e participaram de manifestações contra regimes norte-americanos e árabes; algumas poucas mulheres estiveram bastante envolvidas com a construção da OLP; um número substancial de mulheres jovens entrou no trabalho profissional; e a grande maioria das mulheres transmitiu o nacionalismo palestino para suas filhas e seus filhos.

Desse modo, as mulheres que permaneceram no campo começaram a desenvolver um papel ativo na economia, passando por um processo de proletarização (AL-HAMDANI, 2014), mas, ao mesmo tempo, tendo sua formação educacional qualificada. Por outro lado, aquelas que foram para o exílio, sobretudo na Jordânia, Egito, Síria e Líbano começaram a mobilizar-se através dos vários partidos políticos (WADI, 2009), que todavia não pareciam dar muita importância às questões relacionadas à libertação e emancipação das mulheres (JAD, 2005).

Em 1964, foi fundada a Organização para Libertação da Palestina (OLP), da qual muitas mulheres fizeram parte. Da mesma conferência em que foi estabelecida a OLP também foi resultante o surgimento da União Geral de Mulheres Palestinas em 1965, criada como uma organização de massa para participar da libertação da terra natal das palestinas. No entanto, devido à natureza de sua composição (que consistia majoritariamente de mulheres socialmente privilegiadas), mantinha a estratégia de construir associações de caridade que "forneciam serviços às mulheres" (JAD, 2005, p.220). Para além disso, entre as principais atividades desenvolvidas pela União Geral de Mulheres Palestinas destacam-se aquelas ligadas à participação em conferências diplomáticas (SAYIGH, 2014). 
Em 1967, após a Guerra dos Seis Dias, Israel ocupou militarmente a Cisjordânia e a Faixa de Gaza e anexou Jerusalém Oriental. As mulheres vivendo sob ocupação que entraram no mercado de trabalho eram submetidas às condições de emprego mais precárias. Segundo IslahJad, "a opressão sobre as mulheres trabalhadoras que viviam sob controle israelense era tripla: como palestinas, como trabalhadoras e como mulheres" (JAD, 2005, p. 221).

A derrota de 1967 transformou a OLP em uma organização de massa representativa e seu discurso passou a apontar para a necessidade de organização das mulheres. No entanto, as organizações de resistência palestinas falharam em estabelecer uma pauta para as mulheres como parte da pauta geral da revolução (JAD, 2005).

Com o aumento do número de prisioneiras (que em 1979 já passava de 3000), o envolvimento das mulheres em organizações políticas cresceu (JAD, 2005), o que fez com que os comitês populares passassem a ter papel mais ativo na sociedade palestina, principalmente a partir da década de 1970. Os objetivos e atividades desses comitês variavam, mas todos enfatizavam a necessidade de trabalho produtivo, educação e treinamento vocacional para mulheres, além de envolverem donas de casa em atividades geradoras de renda.

IslahJad (2005) indica quatro razões principais para o aumento do movimento de mulheres na resistência política na Cisjordânia e em Gaza durante o período de 1975 e 1978. A primeira delas é a conquista do direito ao voto para as eleições municipais, que gerou a organização de vários campos de trabalho nas municipalidades, os quais, por sua vez, tornaram-se lugares perfeitos para a promoção de mulheres ativistas. Em segundo lugar, está o crescimento de instituições de Ensino Superior, as quais eram atendidas majoritariamente por mulheres, que se tornariam membros ativos do movimento estudantil. A terceira razão apontada pela autora é o aumento da repressão levada a cabo pelo governo de Begin Shamir Sharon, que exigiu mais determinação do movimento de resistência palestino, fazendo com que as mulheres passassem a dar mais peso à eleição descentralizada de suas lideranças em organizações de base e do movimento estudantil, em detrimento das tradicionais organizações de caridade. Por fim, Jad alude para o fato de que muitas das atividades culturais de resistência passaram a incorporar questões referentes às mulheres.

A derrota de 1967, portanto, abriu um novo período na história da resistência palestina. $\mathrm{O}$ avanço da repressão de Israel obrigou a sociedade civil palestina a procurar novas formas de organização, as quais pudessem fazer frente à ofensiva israelense. Foi a partir desse momento, portanto, que as organizações de base passaram a ter muito mais importância. Por 
serem descentralizadas e terem mais capilaridade na sociedade civil palestina, essas organizações representavam um desafio muito maior às autoridades israelenses do que as tradicionais formas de organização palestina.

No movimento de mulheres, a situação não foi muito diferente e os comitês populares de mulheres palestinas passaram a ter um papel muito mais ativo na sociedade, principalmente a partir da década de 1970. Como ainda não eram alvo direto da repressão sionista, as mulheres tiveram mais liberdade para enviar petições e memorandos para as mais diversas instituições internacionais e personagens importantes (WADI, 2009).

A literatura aponta, no entanto, para o ano de 1978 como o marco para a emergência de um novo movimento de mulheres palestinas. No dia 8 de março desse ano, algumas mulheres palestinas se organizaram em um encontro, do qual resultou a criação do Comitê das Mulheres Trabalhadoras. Constituído majoritariamente por "aquela geração de mulheres que trabalharam em organizações políticas e não eram bem-vindas nas organizações de caridade existentes" (JAD, 2005, p. 223), o comitê iniciou um programa de educação não apenas nas cidades mas também, pela primeira vez, nas vilas e campos de refugiados. As atividades desenvolvidas pelo comitê partiam da crítica do caráter assistencialista das associações de caridade e procuravam ensinar às mulheres habilidades elementares que permitiriam que ajudassem a elas mesmas (HILTERMANN, 1991).

Seguindo a tendência que já vinha acontecendo com os sindicatos e o movimento nacional palestino no geral, o movimento de mulheres logo foi abarcado pelos partidos políticos palestinos. Desse modo, a partir da década de 1980, uma série de novas organizações passou a emergir, cada uma delas ligada a uma tendência política, com destaque para a Federação dos Comitês de Ação das Mulheres Palestinas, União dos Comitês das Mulheres Trabalhadoras Palestinas, Comitê das Mulheres Palestinas (que em 1981 se transformaria na União dos Comitês das Mulheres Palestinas) e o Comitê das Mulheres para Trabalho Social. Apesar dessa divisão, todos os grupos tinham o objetivo comum de envolver o maior número possível de mulheres na resistência nacional.

A organização das mulheres palestinas permitiu que tivessem uma atuação significativa durante a Primeira Intifada ${ }^{7}$. Ricks (2006) demonstra como garotas de Ensino Médio resistiam aos ataques do exército israelense durante o levante palestino através das

\footnotetext{
${ }^{7}$ A Primeira Intifada, como ficou conhecido o levante popular palestino contra a ocupação israelense, teve início em 1987, em Gaza, mas logo se espalhou também pela Cisjordânia. O evento é conhecido como uma das principais manifestações da resistência não violenta palestina.
} 
mais diversas técnicas de resistência não violenta, tais como a realização de grafite nas paredes, o bloqueio de ruas com pedras e a espionagem para garotas e garotos mais velhos. “As escolas públicas eram centros de demonstrações diárias” (RICKS, 2006, p. 91), nas quais as jovens mulheres eram frequentemente protagonistas.

No entanto, mais do que crianças e jovens, a Primeira Intifada conseguiu se capilarizar por grande parte da sociedade palestina, o que levou a que mulheres das mais diversas faixas etárias participassem ativamente do movimento de resistência não violenta.

O que diferencia a Intifada dos anos anteriores em termos de ativismo de mulheres é o fato de que não são apenas estudantes e ativistas de longa geração que participam de confrontos diretos com soldados, mas mulheres de todas as idades e setores da sociedade, especialmente mulheres das vilas e dos campos de refugiados (HILTERMAN, 1991, p. 49, tradução nossa).

Em 1988, foi declarado simbolicamente o Estado da Palestina, estabelecendo o Conselho Superior das Mulheres, o qual reunia as quatro principais organizações de mulheres. Apesar de esse conselho ter começado a discutir mais claramente uma agenda feminista, foi apenas com a construção de centros de estudos das mulheres, nos anos 1990, que se começa a discutir questões, como, por exemplo, a violência doméstica contra as mulheres (WADI, 2009).

Em 1993, com a assinatura dos Acordos de Oslo, Israel retira-se de Gaza, mas, na prática, seu controle sobre os Territórios Palestinos Ocupados se mantem. Os assentamentos de Gaza constituem mais de $30 \%$ do território da faixa e a economia palestina permanece dependente de Israel. Gaza passa a ser administrada, juntamente com a Cisjordânia, pela Autoridade Nacional Palestina, que reconhece o direito de Israel de existir (SAID, 1993). Nesse momento, as possibilidades de construção de um Estado Palestino se tornam mais concretas, mas, assim como o povo palestino, o movimento de mulheres se divide entre apoiadoras dos acordos e aquelas que viam Oslo apenas como uma forma de garantir um Estado sem direitos para os palestinos, e uma traição por parte da OLP.

O grupo que apoiou os acordos formou uma comissão técnica para os assuntos das mulheres que culminou, em 2004, com a criação do Ministério dos Assuntos das Mulheres. O movimento de mulheres passou, então, a funcionar em instituições e organizações, distantes das massas, o que fez com que perdesse muito da sua força (WADI, 2009).

Um efeito desse distanciamento pode ser observado durante a Segunda Intifada (20002005), levante palestino caracterizado por muito mais violência e menor participação popular, em comparação com a Primeira Intifada. Ricks (2006), no entanto, ressalta mais uma vez a importância da resistência das garotas palestinas em idade escolar. Ao escrever suas 
experiências em diários, coletar a história oral de palestinos mais velhos e realizar peças teatrais, as jovens palestinas estavam contribuindo para a preservação da memória palestina e para o fortalecimento da unidade entre os palestinos.

A falência das instituições ligadas à Autoridade Nacional Palestina no avanço das pautas ligadas ao movimento de mulheres abriu espaço para um novo fenômeno na sociedade palestina: a proliferação de Organizações Não Governamentais (ONGs), sobre as quais há um grande debate em relação à sua real autonomia e sua ligação com seus países de origem ${ }^{8}$. O que se sabe, de fato, é que essas organizações até hoje possuem papel relevante na sociedade civil palestina, o que torna seu estudo imprescindível para compreender essa sociedade

\section{A atuação das mulheres na PalestinianWorkingWomanSociety for Development (PWWSD)}

A PalestinianWorkingWomanSociety for Development nasce em 1981, como "União dos comitês das mulheres trabalhadoras palestinas". Seguindo a tendência do período de partidarização dos movimentos sociais, a União tinha inclinações políticas com o Partido Comunista Palestino (HILTERMANN, 1991), o que em grande parte explica a escolha pela ênfase em "mulheres trabalhadoras" em seu nome.

Em 2001, a organização foi oficialmente registrada no Ministério de Interior Palestino como Palestinian Working Woman Society for Development e se caracteriza como uma organização de mulheres palestinas de massa, que contribui para o desenvolvimento da luta feminista dentro das dimensões nacional, social e de desenvolvimento.

A organização aborda a questão dos direitos das mulheres como parte integrante dos direitos humanos. Segundo o folder explicativo da ONG,

\footnotetext{
[...] atingir a liberdade das mulheres e seu desenvolvimento na base dos plenos direitos de cidadania está atrelado ao alcance do progresso social, econômico e democrático a nível comunitário, o que requer o desenvolvimento de uma clara vontade política para eliminar todas as formas de discriminação e a materialização da igualdade de gênero no cotidiano da comunidade dentro dos princípios e concepções de desenvolvimento geral (PWWSD, 2013, p.3, tradução nossa).
}

A atuação da organização baseia-se na concepção de que os direitos das mulheres são violados em dois níveis: pela ocupação israelense e pela legislação vigente nos Territórios Palestinos Ocupados. No primeiro nível, percebe-se uma restrição do movimento de mulheres palestinas devido à presença de checkpoints (postos de controle militar comandados pelo exército israelense), os quais, consequentemente limitam seus direitos à educação e ao acesso a serviços básicos. Não raro, mulheres palestinas são forçadas a dar à luz em checkpoints, são detentas e frequentemente assediadas física e verbalmente nesses postos de controle. Para

\footnotetext{
${ }^{8}$ Para mais referências, veja JAD (2004).
} 
além disso, o confisco de terras restringe a participação econômica das mulheres, já que a maior parte das mulheres economicamente ativas dedica-se à agricultura.

A realidade da ocupação imprime uma série de obstáculos nas mais diversas esferas da vida palestina e o trabalho da organização precisa levar em consideração o aspecto multifacetado dessa sociedade. Segundo uma funcionária da ONG que foi entrevistada, "quando você fala sobre mulheres palestinas, você tem as mulheres que vivem nas vilas, que são diferentes das mulheres que vivem nas cidades, das mulheres marginalizadas que vivem em localidades como a área $\mathrm{C}^{9}$ ou próximas ao muro".

Em relação à legislação vigente nos Territórios Palestinos Ocupados, a PWWSD parte da avaliação de que este conjunto de leis não é capaz de proteger as mulheres ou defender seus direitos, e de que há uma falta de vontade política para a adoção de leis que garantam a igualdade de gênero e os direitos das mulheres. Para além disso, as mulheres são excluídas, de um modo geral, dos processos de tomada de decisão (PWWSD, 2015).

O objetivo da organização é "contribuir em direção à construção de uma sociedade palestina democrática, baseada na igualdade (de gênero), justiça social, e respeito pelos direitos humanos". Além desse objetivo central, a ONG possui três objetivos estratégicos, os quais são: “contribuir para o empoderamento de mulheres (especialmente mulheres trabalhadoras) e o fortalecimento de sua participação e envolvimento em todos os aspectos da vida baseados na igualdade de gênero e direitos humanos das mulheres"; "contribuir para a melhora do bem-estar psicológico das mulheres na comunidade palestina e combater todas as formas de violência contra mulheres e crianças"; e "desenvolver a capacidade e os recursos da PWWSD para fortalecer sua auto-sustentabilidade" ${ }^{\text {. }}$.

De modo a concretizar seus objetivos, a organização desenvolve atualmente três tipos de programas: empoderamento de mulheres, aconselhamento psicossocial e os programas de capacitação, desenvolvidos a partir de escritórios localizados em Nablus, Jenin, Tulkaren, Belém, Gaza e Yatta. A atuação da PWWSD, portanto, se capilariza por quase todo o território da Cisjordânia e de Gaza, mas não alcança de forma direta as mulheres palestinas que vivem dentro das fronteiras do atual Estado de Israel ou as refugiadas que vivem fora dos Territórios Palestinos Ocupados.

\footnotetext{
${ }^{9}$ Como consequência dos Acordos de Oslo,a Cisjordânia foi dividida em áreas A, B, e C. A área A, correspondendo a 2,7\% do total do território, ficaria sob jurisdição civil e militar da Autoridade Palestina; a área B $(25,1 \%$ do território total) estaria sob controle civil da Autoridade Palestina e controle de segurança conjunto entre Israel e Autoridade Palestina. Já a área C, representando a maior parte do território da Cisjordânia (72,2\% do território), estaria sobre controle civil e militar de Israel (AGUIAR, 2011).

${ }^{10}$ Informações disponíveis em: http://www.pwwsd.org/objectives/. Acesso: 23 fev. 2017.
} 
Entre as suas estratégias de atuação, destacam-se os comitês de base, que, como parte do programa de empoderamento, visam fornecer suporte às mulheres eleitas nos conselhos locais, além de monitorar o desempenho das autoridades locais em relação ao seu comprometimento com os princípios de igualdade de gênero e respeito aos direitos das mulheres. A organização também realiza fóruns nos quais as membras de comitês de diversas localidades têm a oportunidade de trocar experiências (PWWSD, 2015).

Para além disso, a PWWSD promove workshops educacionais, com o intuito de alçar a percepção das mulheres palestinas sobre seus direitos. Em 2013, foram realizados 526 workshops, beneficiando 3988 participantes (PWWSD, 2014), enquanto que em 2014 o número deste tipo de workshop realizado caiu para 235, beneficiando 1744 participantes (PWWSD, 2015). Dentre os beneficiados, incluem-se mulheres trabalhadoras, donas de casa, jovens e estudantes mulheres e homens, membras de comunidades de base, mulheres representantes de organizações de mulheres e de direitos humanos, membras de partidos políticos e de conselhos de base, acadêmicas, líderes comunitárias e feministas (PWWSD, 2014).

Seminários e ciclos de estudo também são frequentemente realizados pela organização com o objetivo de contribuir para o empoderamento de mulheres (especialmente mulheres trabalhadoras) e fortalecer sua participação e envolvimento em todos os âmbitos da vida com base na igualdade de gênero e nos direitos humanos das mulheres. No ano de 2014, a PWWSD realizou um seminário na cidade palestina de Nablus, intitulado "O importante papel das mulheres no boicote aos produtos israelenses", o qual contou com a participação de representante do movimento de Boicote, Desinvestimentos e Sanções a Israel (PWWSD, 2015).

A ONG também incentiva a organização de mulheres em cooperativas locais e sindicatos, de modo que advoguem por seus direitos. Segundo relatório publicado pela PWWSD referente aos trabalhos realizados pela organização durante o ano de 2013, "houve um aumento no número de mulheres organizadas em sindicatos e um aumento da efíciência das organizações de base para influenciar e participar na defesa dos seus direitos" (PWWSD, 2014, p. 23, tradução nossa). A mobilização de campanhas que promovam o reconhecimento dos direitos das mulheres em meio à comunidade e pressionem dirigentes políticos também está entre as estratégias da organização.

Nota-se, através de informações obtidas de relatórios da organização, que essas atividades, somadas às visitas de intercâmbio promovidas pela organização entre mulheres de 
diferentes cidades, contribuíram por aumentar o nível de networking das mulheres com diversas organizações de base (PWWSD, 2015), bem como expandir sua disposição para participar e interagir com outras atividades organizadas pela própria PWWSD, como manifestações de rua e trabalhos em meio à comunidade:

\begin{abstract}
Além disso, as mulheres participaram de vários atos de protesto, organizados pela PWWSD e outras organizações de mulheres em reconhecimento ao Dia Internacional das Mulheres, Dia do Trabalho, em apoio a prisioneiros em greve de fome, assim como em manifestações que demandavam reconciliação. A PWWSD constrói e fortalece sua relação com grupos de mulheres, e convida esses grupos a se engajar em trabalho comunitário e participar de várias atividades (PWWSD, 2014, p. 16 , tradução nossa).
\end{abstract}

Desse modo, a atuação da PWWSD não se limita a discussões referentes à questão de gênero como um fim em si mesma, uma vez que a partir de seu trabalho, mais mulheres passaram a se envolver na luta nacional e social. Os relatórios analisados apontam para a construção de atividades nacionais pela organização e "para a criação de fóruns de jovens e mulheres sempre que possível para ativar o papel político das mulheres" (PWWSD, 2014, p. 24, tradução nossa).

Trata-se, portanto, de uma organização que visa fortalecer o papel político das mulheres de modo a se engajarem nas mais diversas esferas da vida pública. Tendo em vista a particularidade do contexto da ocupação israelense na sociedade palestina, o trabalho da PWWSD contribui para que as mulheres palestinas tenham maior conhecimento sobre as violações de direitos humanos cometidas por Israel e que advoguem em defesa dos seus direitos violados:

\begin{abstract}
Os encontros de discussão com ex-presidiárias palestinas e com familiares de prisioneiros palestinos foram concluídos com um número de recomendações para partidos oficiais e populares sobre a necessidade de adotar um plano nacional estratégico para manter a questão dos prisioneiros políticos palestinos vivos e para pressionar por sua liberdade (PWWSD, 2014, p. 24, tradução nossa).
\end{abstract}

Em 2014, diante dos bombardeios de Israel em Gaza ${ }^{11}$, a PWWSD organizou, além de manifestações, declarações, ocupações e encontros com cônsules, uma vigília em frente a sede da ONU demandando um fim à agressão israelense. Durante essa vigília, a organização apresentou uma carta ao secretário-geral da ONU exigindo "o cessar da violência israelense e terrorismo contra o povo palestino na Faixa de Gaza e em Jerusalém Oriental" (PWWSD, 2015, p.29, tradução nossa).

\footnotetext{
${ }^{11}$ Em 2014, a Faixa de Gaza foi submetida a uma intensa ofensiva militar por parte de Israel. O disparador do ataque, que durou 51 dias e deixou um saldo de mortos de 2.205 palestinos e 71 israelenses, foi o sequestro de três jovens israelenses em junho daquele ano, do qual o Hamas, grupo politico que controla a região de Gaza, foi considerado responsável por Israel(RANGEL, 2014).
} 
Ainda como parte do programa de empoderamento de mulheres, a organização fornece consultas jurídicas e representa mulheres na corte de justiça, de forma a expandir os horizontes das palestinas para a obtenção de seus direitos. Os temas pleiteados por mulheres se referem desde a questões trabalhistas até a status individual e questões de herança. Esse tipo de trabalho que tornou a PWWSD referência para mulheres e demais organizações jurídicas (PWWSD, 2014).

Em 2013, foram fornecidas 497 consultas legais (realizadas em escritórios, em campo ou através de uma linha aberta de ligações) e 261 casos foram apresentados à corte (PWWSD, 2014). Em 2014, a organização presenciou uma pequena diminuição desses números. Ao longo do ano, foram realizadas 440 consultas legais (em escritório e em campo), 42 consultas através da linha aberta e 236 casos foram apresentados à corte (PWWSD, 2015).

O empoderamento econômico de mulheres também está entre as estratégias da organização. Desse modo, a PWWSD atua na formação de cooperativas que contribuíram para que mulheres se tornassem independentes economicamente. Os grupos que participaram da formação de cooperativas tornaram-se capazes de se engajar no processo de produção, distribuição e na determinação de opções a serem produzidas.

Essas cooperativas recebem o devido apoio e acompanhamento da ONG depois de sua criação. Em 2014, por exemplo, foram realizados 8 treinamentos para cooperativas localizadas na Cisjordânia, o acompanhamento de workshops em Gaza e a realização de exposições com produtos produzidas pelas mulheres de cooperativas (PWWSD, 2015).

O programa de aconselhamento psicossocial contribui, em conjunto com os programas de empoderamento e de capacitação, para o alcance do objetivo central da organização. Através do programa de terapia, por exemplo, as mulheres recebem atendimento na forma individual, familiar, em grupo ou até mesmo através de uma linha telefônica específica. Tratase de uma forma de fortalecer a saúde mental de mulheres e desenvolver sua capacidade de enfrentar situações de pressão às quais são frequentemente submetidas.

Segundo o relatório analisado sobre as atividades referentes a 2013, durante este ano foram realizados 473 serviços de terapia individual psicossocial, 354 consultas psicossociais e 1426 sessões de terapia (PWWSD, 2014). Em 2014, 426 pessoas foram beneficiadas com os serviços de terapia psicossocial individual, foram realizadas 286 consultas psicossociais e 1359 sessões de terapia (PWWSD, 2015).

A percepção da comunidade como um todo em relação à violência contra mulheres é uma questão bastante importante para a organização. Assim, a PWWSD organizou diversas 
atividades de advocacy e lobby, de modo a influenciar a opinião pública em relação a esse tipo de violência, utilizando-se de vários tipos de ações: ocupações, memorandos, petições, declarações, comunicados de imprensa, conferências, marchas e manifestações.

Nesse sentido, a ONG se utiliza de vários tipos de mídia como uma "ferramenta para aumentar a percepção das mulheres sobre seus direitos, assim como aumentar a sensibilidade da comunidade local sobre as questões das mulheres"(PWWSD, 2015, p. 40, tradução nossa). Em 2014, a organização produziu um pequeno documentário sobre mulheres palestinas refugiadas, 6 programas de rádio de curta duração, além de produzir relatórios, pôsteres e declarações sobre a situação das mulheres palestinas (PWWSD, 2015).

Finalmente, destaca-se o programa de capacitação, o qual consiste na realização de atividades que permitam às palestinas "alcançar um ponto em que possam trabalhar individualmente e independentemente e possam utilizar todos os recursos disponíveis para defender seus direitos" (PWWSD, 2014, p. 12, tradução nossa). Ao longo do ano de 2013, foram realizados 25 cursos de treinamento, os quais beneficiaram 461 mulheres, homens e garotas. Os cursos focaram em habilidades de liderança, legislação do Conselho Local, habilidades de negociação, técnicas de rede e comunicação, advocacy e realização de campanhas (PWWSD, 2014, p. 21).

Para além disso, a PWWSD realiza workshops de treinamento, os quais "contribuíram para aumentar o conhecimento e as habilidades dos participantes e abrir horizontes para expandir sua habilidade de influenciar e transferir seu conhecimento para outros grupos" (PWWSD, 2015, p.20, tradução nossa). Em 2014, foram realizados 32 workshops de treinamento nas várias localidades da PWWSD, beneficiando 482 participantes, que incluem, além dos já beneficiados pelos workshops educacionais, mulheres de cooperativas e estagiárias de direito (PWWSD, 2015).

Com o intuito de cumprir seu terceiro objetivo estratégico (“desenvolver a capacidade e os recursos da PWWSD para fortalecer sua auto-sustentabilidade"), a ONG realiza constantemente atividades de treinamento para seus corpo de funcionários e voluntários, além de encontros de acompanhamento das atividades e trocas de experiências. Em 2013, foram realizados encontros mensais entre membros dos vários escritórios da organização (PWWSD, 2014) e, em 2014, para além desses encontros, a PWWSD realizou um total de 12 atividades de treinamento sobre temas como acessibilidade, uso de redes sociais e de bases de dados (PWWSD, 2015). 
Ademais, a organização desenvolve atividades geradoras de renda para seu orçamento. Através de uma exposição permanente intitulada "Lamasat", realizada em um dos escritórios da organização, e de sua página de Facebook, produtos feitos por mulheres de cooperativas e de comunidades de base são expostos e vendidos. Exposições temporárias também são realizadas nas várias localidades em que a PWWSD atua, com o mesmo objetivo.

Entre os principais desafios enfrentados pela organização, destacam-se aqueles relacionados a questões estruturais, como a própria ocupação israelense, que, além de violar uma série de direitos humanos, impacta diretamente a locomoção de membros da ONG entre Cisjordânia e Gaza, e o sistema patriarcal, que dificulta a participação das mulheres na política. Segundo a organização:

Este sistema prevalecente limita o acesso das mulheres à justiça e são colocadas pressões sobre as mulheres, tanto pela sociedade quanto pela família, para não buscarem seus direitos, como o direito à herança (PWWSD, 2015, p.63, tradução nossa).

Para além disso, a ineficiência do parlamento palestino, que afeta na implementação de leis que garantiriam direitos às mulheres, combinado com um fraco desempenho do judiciário, desencorajam mulheres a buscarem canais legais para advogarem por seus direitos. Em 2014, merece ainda uma especial atenção o adiamento das eleições parlamentares. De acordo com a PWWSD:

\footnotetext{
Eleições são um passo essencial para a democratização da comunidade e o envolvimento das mulheres no processo de tomada de decisões. $\mathrm{O}$ fato de as eleições do parlamento palestino não terem ocorrido como planejadas provocou uma mudança nas atividades que focavam no aumento da participação de mulheres nessas eleições (PWWSD, 2015, p. 63, tradução nossa).
}

Um outro desafio enfrentado pela organização, relacionado à dinâmica da política interna nos Territórios Palestinos Ocupados, é o crescimento de grupos reacionários e fundamentalistas, que demonstram hostilidade em relação aos direitos humanos em geral e aos direitos das mulheres em específico. Esses grupos refletem também uma moralidade que dificulta a inserção de mulheres na vida pública.

Por fim, o trabalho da PWWSD também esbarra em dificuldades econômicas, as quais estão direta ou indiretamente ligadas à dinâmica da ocupação israelense.

[A deterioração econômica] ainda afeta a tendência das mulheres de se empoderarem e advogarem por seus direitos. As mulheres priorizam as necessidades diárias de seus filhos, ao passo que em muitos casos mulheres trabalhadoras estão dispostas a abandonar seus direitos para manter sua fonte de renda. Embora a PWWSD tenha criado oportunidades econômicas para muitas mulheres, a escassez 
de oportunidades operacionais e financeiras para mulheres ainda constitui uma condição econômica desafiadora (PWWSD, 2015, p. 63, tradução nossa).

A falta de fundos e de serviços especializados impacta diretamente na realização do trabalho de base da organização, já que implica em uma redução da quantidade de atividades realizadas. Todavia, por se tratar de uma questão que afeta os Territórios Ocupados de maneira generalizada, cada vez mais pressão é colocada sobre a ONG, devido à escassez de outras instituições que promovam serviços como o atendimento psicológico.

Pese as dificuldades enfrentadas pela organização, seu trabalho cumpre um importante papel no interior da sociedade palestina. Nota-se mais uma vez como os três tipos de programa da ONG estão bastante inter-relacionados, já que a capacitação de mulheres para que atuem da forma independente, aliada à manutenção de sua saúde mental, contribui para seu empoderamento político e social. As práticas da organização, portanto, norteadas por objetivos bem definidos, tornam a PWWSD uma das mais importantes organizações de mulheres existentes hoje nos Territórios Palestinos Ocupados, promovendo a defesa de uma sociedade livre de discriminação e que incorpore o princípio da igualdade de gênero na vida diária da comunidade.

\section{Considerações Finais}

Quando analisamos a literatura referente à resistência não violenta no contexto específico da Palestina, notamos uma diferença na abordagem dos autores antes e depois dos Acordos de Oslo, realizados durante a década de 1990. Enquanto estudos anteriores à realização dos Acordos tendem a apostar nesse tipo de resistência como técnica para superação da dominação israelense (AWAD, 1984; SHARP, 1989), estudos mais recentes preocupam-se mais em demonstrar que a resistência não violenta na Palestina existe, pese sua invisibilidade na comunidade internacional (MUNAYER, 2015; O'CONNOR 2005). Todavia, nota-se um ceticismo maior na análise destes últimos autores quanto à possibilidade da resistência não violenta como uma única forma de superação do domínio israelense.

A partir da pesquisa bibliográfica também foi possível notar que o movimento de mulheres palestinas se utilizou das três classes de métodos de resistência não violenta nomeadas por Sharp (1989) durante o período estudado. Formas simbólicas de protesto não violento estiveram presentes desde o fim do século XIX, quando as mulheres iniciaram sua atuação no movimento de resistência política, (KAZI, 1987; WADI, 2009) e, em 1917, as mulheres passaram a participar das grandes manifestações de rua. 
As mulheres palestinas também se envolveram, de forma organizada, em movimentos de não cooperação. Em abril de 1933, por exemplo, as mulheres de Jerusalém, participaram de um boicote nacional e, em 1936, tiveram papel de vanguarda na Greve Geral da Palestina, que durou seis meses (SAYIGH, 2004).

Em relação à terceira classe de método de resistência não violenta - a intervenção não violenta - encontramos uma ampla atuação do movimento de mulheres, sobretudo no que se refere à criação de instituições independentes. 1921 é considerado pela literatura o ano no qual as mulheres começaram seu primeiro grande movimento organizado em Jerusalém (KAZI, 1987; WADI, 2009). Posteriormente, outras organizações de mulheres surgiram, como a União Geral de Mulheres Palestinas, em 1965, e o Comitê das Mulheres Trabalhadoras, em 1978, somando-se às tradicionais formas de organização de mulheres em instituições de caridade (JAD, 2005).

Com base no material analisado da ONG Palestinian Working Woman Society for Development, também foi possível notar a presença das três classes de método de resistência não violenta definidos por Sharp (1989) em sua atuação. A partir da realização de marchas e manifestações de rua, por exemplo, a organização se utiliza de formas simbólicas de protesto não violento para advogar pela defesa dos direitos das mulheres e outras questões relacionadas diretamente a problemas causados pela ocupação israelense.

Além disso, a produção de seminário com representante do movimento de Boicote, Desinvestimento e Sanções a Israel (BDS) demonstra a relevância que a organização dá a movimentos de não cooperação. Por fim, a realização de ocupações, a organização de comitês de base, fóruns de mulheres e jovens, cooperativas autônomas e o estímulo à organização das mulheres em sindicatos e demais formas de instituição independente são uma clara demonstração da presença da intervenção não violenta entre as técnicas de atuação da ONG.

Tendo como concepção a defesa dos direitos das mulheres como parte integrante dos direitos humanos, a Palestinian Working Woman Society for Development, atua na defesa de uma sociedade palestina democrática e que incorpore esses direitos. A organização contribui, desse modo, através do uso da resistência não violenta, para o enfrentamento da dominação israelense, a qual viola uma série desses direitos.

\section{Referências}

ABU-EL-HAJ, Jawdat. A geopolítica e o conflito palestino-isralense: dos Acordos de Oslo à Primavera Árabe. História (São Paulo), vol. 33, n. 2, jul/ dez 2014. 14-36. 
AGUIAR, Paula Hograwe. Os acordos de Oslo (1993): consequência e causa das intifadas. Porto Alegre. 2011. 74 p. Monografia de conclusão de curso - Faculdade de Ciências Econômicas da UFRGS.

ALLEN, Lori. Palestinians Debate "Polite" Resistance to Occupation.Middle East Report, n. 225, 2002. 38-43.

AWAD, Mubarak E. Non-violent resistance: a strategy for the Occupied Territories. Journal of Palestine Studies, vol. 3, n. 4, 1984. 22-36.

CHENOWETH, Erica; STEPHAN, Maria J. Drop Your Weapons. When and Why Civil Resistance Works. Foreign Affairs, julho/ agosto 2014.Disponível em: <https://www.foreignaffairs.com/articles/libya/2014-06-16/drop-your-weapons >. Acesso em: 03 dez. 2015.

CHOMSKY, Noam. Chomsky desnuda a "Guerra ao Terror". Outras Palavras, 22 de dezembro de 2015. Disponível em: <http://outraspalavras.net/posts/chomsky-desnuda-aguerra-ao-terror/>. Acesso em: 18 set. 2016.

COSTA, Antonio Luiz M. O começo da Terceira Intifada. Carta Capital, 11 de outubro de 2015. Disponível em: <http://www.cartacapital.com.br/internacional/o-comeco-da-terceiraintifada-9408.html>. Acesso em: 18 set. 2016.

DUARTE, João Paulo Gusmão P.Guerra ao terror: uma guerra na sociedade de controle. In: $3^{\circ}$ ENCONTRO NACIONAL ABRI 2011, 2011, São Paulo.Associação Brasileira de Relações Internacionais, Instituto de Relações Internacionais - USP. Disponível em: $<$ http://www.proceedings.scielo.br/scielo.php?script=sci_arttext\&pid=MSC00000001220110 00200035\&lng=en\&nrm=abn>. Acessoem: 18 set. 2016.

DUDOUET, Véronique. Nonviolent resistence and conflict transformation in power asymmetries. Berghof Research Center for Constructive Conflict Management, 2008, 127.

FLEISHMANN, Ellen L. The emergence of the Palestinian women's movement, 192939.Journal of Palestine Studies, vol. 29, n. 3, 2000.16-32.

FLINT, Guila. Intifada das facas cria clima de histeria coletiva em Israel. Opera Mundi, 14 de novembro de 2015.2 Disponível em: 〈http://operamundi.uol.com.br/conteudo/noticias/42263/intifada+das+facas+cria+clima+de+h isteria+coletiva+em+israel.shtml\#>. Acessoem: 18 set. 2016.

HILTERMANN. Joost R. The women's movement during the uprising.Journal of Palestine Studies, vol. 20, n. 3, 1991. 48-57.

JAD, Islah. "From salons to the popular comittees: Palestinian women, 1919-89". In: PAPPÉ, Ilan. The Israel/ Palestine question. Londres: Routledge, 2005. Cap.12, 217-231.

JAD, Islah. The NGO-isation of Arab Women's Movements.IDS Bulletin, vol. 35, n. 4, 2004. $34-42$.

KAZI, Hamida. Palestinian women and the national liberation movement: a social perspective. In: Khamsin: women in the Middle East. Londres: Zed Books, 1987. P. 26-39. 
MAST, Edward; EL-ZABRI, Haithen. Nakba: the ongoing ethnic cleansing of Palestine. A concise guide to history and issues.Palestine Information Project, 2015, 24p.

MIDDLE EAST TASK FORCE. Palestinian nonviolent resistance to occupation since 1967.AFSC Middle East Resource series, 2005.

MUNAYYER, Y. Palestine's Hidden History of Nonviolence. ForeignPolicy, 18 de maio de 2011. Disponível em: <http://foreignpolicy.com/2011/05/18/palestines-hidden-history-ofnonviolence-2/>. Acessoem: 03 dez. 2015.

NASSAR, Ibrahim. Resistance should be our strategic choice. Disponível em: <http://www3.e-joussour.net/en/node/1951>. Acesso em: 13 mar. 2016.

NASSAR, Ibrahim. WhatisNormalization? AlternativeInformation Centre, 14 de novembro de 2013. Disponível em: <http://alternativenews.org/archive/index.php/blogs/othercomentators/7381-what-is-normalization>. Acessoem: $11 \mathrm{dez} .2015$.

NASSER, Randa; BARGHOUTI, Fidaa; MOUSA, Janan. Feminist attitudes and praxis among Palestinian women activists.Feminist Formations, vol. 22, n. 3, 2010. 146-175.

O'CONNOR, Patrick. The invisibility of Palestinian Nonviolent Resistance in the New York Times.The Electronic Intifada, 23 deoutubro de 2005. Disponível em: $<$ https://electronicintifada.net/content/invisibility-palestinian-nonviolent-resistance-new-yorktimes/5775> .Acessoem: 11 abr. 2017.

LIBCOM LIBRARY. - Palestinian women in the Occupied Territories: an interview with Laila al-Hamdani.Disponível em: <https://libcom.org/library/palestinian-women-occupiedterritories-interview-laila-al-hamdani>. Acessoem: 19 jul. 2016.

PALESTINE LIBERATION ORGANIZATION.The struggle of Palestinian women. Beirute: PLO, 1975.

PALESTINIAN WORKING WOMAN SOCIETY FOR DEVELOPMENT (PWWSD). Disponívelem: <http://www.pwwsd.org/>. Acessoem: 09 set. 2016.

2013, 14p.

Palestinian Working Woman Society for Development. PWWSD, PWWSD, 2013, 59 p.

Palestinian women's participation in peace negotiations.Ramallah: PWWSD, 2014, 57 p.

Grass roots approach:anual narrative report - 2013. Ramallah:

Grass roots approach: anual narrative report - 2014. Ramallah, 2015, 64 p.

RANGEL, Carmen. A mais sangrenta ofensiva militar em uma década. El país, 28 de dezembro de 2014. Disponível em: <https://brasil.elpais.com/brasil/2014/12/26/internacional/1419624080_095754.html〉. Acesso em: 17 jul. 2017. 
RESENDE, F. A.; ROSSIGNOLI, L. O conflito Israel/Palestina como acontecimento jornalístico: análises de narrativas do jornal Folha da Manhã (1936/1946). Galaxia (São Paulo, Online), n. 30, dez. 2015. 86-98. Disponível em http://dx.doi.org/10.1590/198225542015223289. Acessoem: 03 ago. 2017.

RICKS, Thomas M. In their own voices: Palestinian High School girls and their memories of the Intifadas and nonviolent resistance to Israeli occupation, 1987 to 2004 . NWSA Journal, vol. 18, n. 3, 2006, 88-103.

RIGBY, Andrew. Palestinian resistance and nonviolence. $1^{\mathrm{a}}$ edição. Jerusalém: PASSIA, 2010, 59 p.

ROCKWELL, Susan. Palestinian Women Workers in the Israeli-Occupied Gaza Strip.Journal of Palestine Studies, vol. 14, n. 2, 1985. 114-136.

SAID, Edward W. Orientalismo: o oriente como invenção do ocidente. Tradução de RosauraEichenberg. São Paulo: Companhia das Letras, 2007. 523 p.

SAID, Edward. The Morning After.London Review of Books, vol. 15, n. 20, 21 Outubro 1993. 3-5.

SAYIGH, Rosemary. Palestinian women: triple burden, single struggle. Libcomlibrary. Disponível em: <https://libcom.org/library/palestinian-women-triple-burden-single-strugglerosemary-sayigh>. Acesso em: $01^{\circ}$ maio 2016.

SEVERINO, Antonio J. Metodologia do trabalho científico. $23^{a}$ edição. São Paulo: cortez, 2007. 303 p.

SHALOUB-KEVORKIAN, Nadera.The politics of birth and the intimacies of violence against Palestinian women in Occupied East Jerusalem.British Journal of Criminology. N. $55,2015$.

SHARP, Gene. Poder, luta e defesa: teoria e prática da ação não-violenta. Tradução de Getúlio Bertelli. São Paulo: Edições Paulinas, 1983. 274 p.

SHARP, Gene. The Intifadah and Nonviolent Struggle. Journal of Palestine Studies, vol. 19, n. 1, 1989. 3-13.

WADI. Shadi. Feminismos de corpos ocupados: as mulheres palestinianas entre duas resistências. Coimbra, Portugal. 2009. 87p. Dissertação (Mestrado em Estudos Feministas) Faculdade de Letras da Universidade de Coimbra.

WOMEN'S CENTER FOR LEGAL AID AND COUNSELLING (WCLAC).Women's voices: glimpses of life under occupation. Ramallah: Batn el-Hawa, 2012.

ZAATUT, Amarat; HAJ-YAHIA, Muhammad M. Beliefs about wife beating among Palestinian women from Israel: the effect of their endorsement of patriarchal ideology. Feminism \& Psychology, 2016. 1-21 